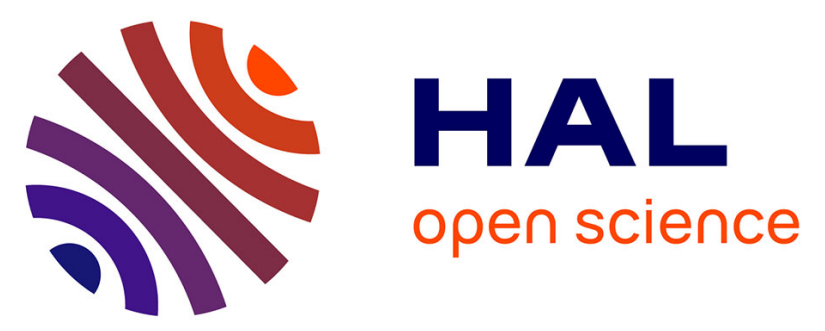

\title{
Explore less to control more: why and when should plants limit the horizontal exploration of soil by their roots?
}

Henri de Parseval, Luc Abbadie, Sébastien Barot, Jacques Gignoux, Jean-Christophe Lata, Xavier Raynaud

\section{To cite this version:}

Henri de Parseval, Luc Abbadie, Sébastien Barot, Jacques Gignoux, Jean-Christophe Lata, et al.. Explore less to control more: why and when should plants limit the horizontal exploration of soil by their roots?. Oikos, 2016, 125 (8), pp.1110-1120. 10.1111/oik.02726 . hal-01233724

\section{HAL Id: hal-01233724 \\ https://hal.sorbonne-universite.fr/hal-01233724}

Submitted on 25 Nov 2015

HAL is a multi-disciplinary open access archive for the deposit and dissemination of scientific research documents, whether they are published or not. The documents may come from teaching and research institutions in France or abroad, or from public or private research centers.
L'archive ouverte pluridisciplinaire HAL, est destinée au dépôt et à la diffusion de documents scientifiques de niveau recherche, publiés ou non, émanant des établissements d'enseignement et de recherche français ou étrangers, des laboratoires publics ou privés. 


\section{Explore less to control more: why and when should plants limit the horizontal exploration of soil by their roots?}

Henri de Parseval ${ }^{1}$, Luc Abbadie ${ }^{1}$, Sébastien Barot ${ }^{1}$, Jacques Gignoux ${ }^{1}$, Jean-Christophe Lata $^{1,2}$ and Xavier Raynaud ${ }^{1}$

${ }^{1}$ Sorbonne Universités, UPMC Univ. Paris 06, CNRS, INRA, IRD, Univ Paris Diderot Paris 7, UPEC, Inst. of Ecology and Environmental Sciences - Paris, UMR 7618, Bât F, 7, quai Saint-Bernard, FR-75252 Paris CEDEX 5, France

${ }^{2}$ Dept of Geoecology and Geochemistry, Inst. of Natural Resources, Tomsk Polytechnic University, Lenin Avenue 30, RU-634050 Tomsk, Russia

Corresponding author: H. de Parseval, Sorbonne Universités, UPMC Univ. Paris 06, CNRS, INRA, IRD, Univ Paris Diderot Paris 7, UPEC, Inst. of Ecology and Environmental Sciences - Paris, UMR 7618, Bât F, 7, quai Saint-Bernard, FR-75252 Paris CEDEX 5, France. E-mail: deparseval@phare.normalesup.org

Decision date: $30-$ Sep-2015

This article has been accepted for publication and undergone full peer review but has not been through the copyediting, typesetting, pagination and proofreading process, which may lead to differences between this version and the Version of Record. Please cite this article as doi: [10.1111/oik.02726]. 


\begin{abstract}
In ecosystems limited by soil nutrients, some plants show a restricted horizontal distribution of their roots. We explored the hypothesis that this particular pattern is a foraging strategy emerging from trade-offs between soil exploration (that increases the pool of nutrients available for plants) and the local control of nutrient cycling within the soil that we call soil occupation. We developed two general analytical models of the cycling of a limiting nutrient in a plant population that is not limited by water. They allowed to explore how plant productivity is affected when roots do not exploit the whole soil available and to determine the conditions for which plant nutrient stock is maximized when plants limit their exploration of soil. We predict that a restricted exploration strategy can be beneficial when (1) there is at least one trade-off between a nutrient cycling parameter and soil exploration, (2) nutrient availability in the unexplored soil is poor and (3) the area of soil explored by plants is stable over time. The exploration limitation strategy results in spatially heterogeneous and nutrient-conservative ecosystems. Our results should apply well to perennial tussock grasses within tropical nutrient-limited ecosystems and raises interesting cues for the construction of more sustainable agro-ecosystems. Overall, our study underlines the importance of considering the multiplicity of root-soil interactions and of their scales when considering root foraging strategies.
\end{abstract}




\section{Introduction}

Root distribution within the soil affects the functioning of plant-soil systems at different scales. At the millimetre to centimetre scale, root density alters nutrient uptake efficiency, but also plant feedbacks on nutrient availability and microbial activities through root exudation (Hinsinger et al. 2009). At the scale of individual plants, the pool of soil water and available nutrients depends on the distribution of these resources, and on the size and the shape of the root system (Lynch 1995, Pagès 2011). At the plant population and community scales, inter-species root distribution influences the intensity and the outcome of competitive and facilitative interactions between individual plants (Casper and Jackson 1997, O’Brien and Brown 2008). All these mechanisms interact with each other and affect both plant productivity and the overall nutrient cycling within ecosystems. Understanding how horizontal and vertical heterogeneities in root distribution across time and space affect plant mineral nutrition is therefore essential. We focus here on the horizontal distribution of roots and consider soil exploration defined as the area of soil containing all or a significant amount of the roots of a plant or a population of plants.

An intuitive view is that, in ecosystems limited by belowground resources, soil exploration should be more important than in resource-rich systems, thus increasing the amount of resources potentially available to plants. This view is backed by empirical data, especially in the case of water (Casper et al. 2003). However, a contrasting pattern can also be observed in ecosystems such as savannas and grasslands, where some plant species show a limited horizontal distribution of roots. For example, in a nutrient-limited African savanna, dominant tussock grasses of the Andropogoneae supertribe leave the soil between tufts relatively unexplored (Lata et al. 2000, Abbadie et al. 2006). This pattern is also found for other tropical tussock grass species (Groot et al. 1998) as well as in some shrub- and small tree-based arid ecosystems (Hartle et al. 2006, Guevara et al. 2009). On the contrary, in temperate grasslands, root distribution is more homogeneous in space and root systems of individuals often overlap whether they belong to the same species or not (Frank et al. 2010, 2015).

Cases of restricted horizontal exploration of soil by roots can be explained by distinct, but not mutually exclusive hypotheses. First, the limited exploration of soil can be a mere outcome of low plant productivity, physiological constraints or the costs of root construction (Lynch and Ho 2005). However, this does not seem to be the case for species such as Hyparrhenia diplandra in the humid savanna of Lamto, Côte d'Ivoire, that have a high productivity despite a limited availability of nutrients (Abbadie et al. 2006). This suggests that other explanations should be considered. Second, plant rooting patterns may simply reflect the underlying pattern of resource distribution: it is well established that plants preferentially proliferate roots within resource hotspots (Hodge 2004). This kind of behaviour can be coupled with processes such as the aboveground interception of litter, or stem-flow that tend to concentrate resources right under plant canopy (Wezel et al. 2000). The fact that some nutrients (e.g. nitrate) are more abundant in deep soil horizons may also favour in-depth exploration at the expense of horizontal exploration (Lynch 2013). Third,

\footnotetext{
'This article is protected by copyright. All rights reserved.'
} 
the limitation of soil exploration may be due to a territorial behaviour characterized by the avoidance of competitors (Gersani et al. 1998) or to allelopathy (Schenk et al. 1999). However, data on grass tufts of the humid savanna of Lamto suggest that their distribution is not explained by competitive interactions (Abbadie et al. 2006).

A common shortcoming of all these hypotheses is that they do not explicitly take into account the feedback of roots on soil processes through exudation and inputs of dead root material. Hereafter we call "soil occupation" the ability of plants to control efficiently a given process of the cycling of a nutrient in the area of soil they explore, for example by enhancing resource availability. Considering relationships between soil occupation and soil exploration, we explore a fourth hypothesis that takes into account this feedback between roots and resource availability: we propose that the concentration of roots in a small soil volume can be considered, at least in some cases, as a plant strategy to improve plant nutrient uptake through a better control on nutrient cycling.

To develop this hypothesis, we focus on the theoretical case of a plant population that is limited by any soil nutrient (e.g. P, N, K...) but not by water or light, and with no interplant competition. Within this framework, if roots are only considered as absorbing organs, a reduced soil exploration should not be considered as an efficient strategy for two main reasons. First, reducing the area of explored soil decreases the pool of soil nutrients potentially available for plants. For example, if inputs of nutrients to the ecosystem occur mainly as a homogeneous deposition of mineral nutrients through winds or rain at the landscape scale, reducing the lateral exploration of soil by roots deprives plants of a proportional part of this deposition. Second, smaller distances between roots of individual plants would create intra-individual, inter-root competition that increases the cost of nutrient absorption (Ge et al. 2000).

However, the exploitation of a nutrient pool often relies on mechanisms others than mere root absorption: roots also influence soil processes by various ways including exudation, respiration, the modification of soil pH etc. (see Hinsinger et al. 2011). Considering these mechanisms leads to the hypothesis that soil exploration and soil occupation can be, in some cases, inversely correlated. Indeed, if an individual plant allocates a constant fraction of its biomass to roots, the restriction of soil exploration should lead to an increase in its root density, which could in turn increase its capacity to control local nutrient fluxes. This enhanced control could thus compensate for the reduced access to nutrients. A large part of soil nutrients are not directly available for uptake and some plants develop "mining" behaviours. For example, some plants couple the exudation of carboxylates (e.g. citrate) that trigger phosphorus availability to the development of "cluster roots" (Lambers et al. 2006). Similarly, the rhizosphere priming effect that allows plants to stimulate mineralization within their zone of influence may depend on root density (Shahzad et al. 2012). The efficiency of nutrient cycling can also depend on the activation or inhibition of soil microbial activities. For example, the biological inhibition of nitrification in tropical savannas is directly correlated to root density (Lata et al. 2000) and this process could reduce mineral losses by avoiding leaching or denitrification at the ecosystem scale (Boudsocq et al. 2009). Finally, processes such as leaching or pre-emption

\footnotetext{
'This article is protected by copyright. All rights reserved.'
} 
by competing microorganisms or plants tend to reduce the quantity of available nutrients to a given plant individual. Reducing the distance of transport from mineralized nutrients to the roots should minimize this risk. Increasing local root density by reducing soil exploration should reduce the distance between dead and living roots and thus favour the recycling of nutrients released from root decomposition (Abbadie et al. 1992, 2006). Based on these examples, we postulate the existence of inverse correlations of soil exploration and occupation. Our main objective is to assess the hypothesis that such tradeoffs can lead to exploration strategies that leave part of the soil unexplored by plants. We also evaluate the consequences of this restricted root exploration for some ecosystem properties, such as soil nutrient stock or nutrient losses.

To tackle these questions, we developed and analysed two simple models describing the cycling of a limiting nutrient using a mathematical framework derived from Barot et al. (2007) and considering different formulations to describe our hypothetical trade-off. Soil nutrients are considered in both their unavailable (fixed within the organic matter) and available (in the soil solution) forms. The first model considers the area of soil explored by plants to be fixed (i.e. population growth is at equilibrium and the explored and unexplored areas are fixed) whereas the second considers a dynamic equilibrium between these two areas (the total area explored is fixed but unexplored area can switch to explored and vice versa).

\section{Material and Methods}

\section{Models descriptions}

\section{Spatial organization of the plant-soil system}

For simplicity, we used an implicit representation of space in which the soil is divided on the horizontal plane into two distinct areas: the soil that is explored (E) or unexplored (U) by roots. This is a discrete approximation of the horizontal distribution of roots, which is generally more continuous in the field (e.g. Lata et al. 2000). We assumed that, below a threshold value of root density, most of the soil nutrients are out of reach of the fine roots. Neglecting possible spatial heterogeneities, we assumed a constant and homogeneous rate of aboveground litter and other nutrient inputs to the modelled area.

Parameter e quantifies soil exploration, defined as the proportion of soil surface explored by roots $(\mathrm{e}=\mathrm{E} /(\mathrm{E}+\mathrm{U})$; Fig. 1). This value integrates all the processes occurring at lower scales: the rhizospheres of selected roots (Hinsinger et al. 2009) and the below-ground zone of influence of individual plants (Casper et al. 2003), and their respective dynamics. We assumed that the plant population has reached its population equilibrium. We supposed soil exploration e to be constant by hypothesizing that (i) plant mortality is perfectly compensated by the birth of new individuals and (ii) changes in the explored/unexplored status of the soil are solely due to plant demography. We thus considered pools of the limiting mineral nutrient to be at equilibrium.

\footnotetext{
'This article is protected by copyright. All rights reserved.'
} 


\section{Compartments of the nutrient cycle}

The cycling of a limiting nutrient (e.g. nitrogen or phosphorus) is modelled in the explored $(E)$ and unexplored $(\mathrm{U})$ areas. Nutrient fluxes between plant tissues $\left(\mathrm{P}_{\mathrm{E}}\right)$, unavailable nutrients pools, such as organic nutrients $\left(\mathrm{D}_{\mathrm{E}}\right.$ and $\left.\mathrm{D}_{\mathrm{U}}\right)$ and available mineral nutrients pools $\left(\mathrm{N}_{\mathrm{E}}\right.$ and $\mathrm{N}_{\mathrm{U}}$ ), are expressed in $\mathrm{kg}$ Nutrient.ha ${ }^{-1} \cdot \mathrm{yr}^{-1}$. Total nutrient contents per unit of soil surface $(\mathrm{P}, \mathrm{D}, \mathrm{N})$ at the whole system scale were calculated using weighted averages:

$$
\begin{aligned}
& \mathrm{P}=e \mathrm{P}_{\mathrm{E}} \\
& \mathrm{D}=\mathrm{e} \mathrm{D}_{\mathrm{E}}+(1-\mathrm{e}) \mathrm{D}_{U} \\
& \mathrm{~N}=\mathrm{e} \mathrm{N}_{\mathrm{E}}+(1-\mathrm{e}) \mathrm{N}_{U}
\end{aligned}
$$

The total stock of nutrients in the system is then:

$\mathrm{T}=\mathrm{P}+\mathrm{D}+\mathrm{N}$

\section{Nutrient fluxes in the plant-soil system}

Inputs of nutrients to the ecosystem are uniform over space and time and occur at rates $i_{D}$ for unavailable nutrients and $i_{N}$ for available nutrients. These fluxes correspond to rains and dust that bring nutrients in the mineral or organic form (Abbadie et al. 2006). Losses of nutrients from the system can be due to mechanisms such as fire, volatilization, harvest or leaching. We modelled them as donor-controlled and proportional to the compartment stocks, with coefficients $l_{\mathrm{P}}, 1_{\mathrm{D}}$ and $l_{\mathrm{N}}$ (for plants, unavailable and available nutrient pools, respectively; see equations below).

Nutrient cycling in our model includes three processes: (i) uptake of available nutrients by plant roots, (ii) plant losses to the unavailable nutrient pool, and (iii) flux from the unavailable to the available nutrient pools (hereafter called "mineralization"). Since nutrient uptake depends on both plant root biomass and nutrient availability in the soil, we modelled it as a controlled, donor-receiver flux proportional to $\mathrm{P}_{\mathrm{E}}$ and $\mathrm{N}_{\underline{E}}$ (type I functional response), with a constant coefficient $u_{N}$ (Barot et al. 2007). Fluxes of organic nutrients between plants $\left(\mathrm{P}_{\mathrm{E}}\right)$ and soil unavailable nutrients $\left(\mathrm{D}_{\mathrm{E}}\right)$ occur through organ mortality and root exudation, and increase the inputs of nutrients to soil detritus. This flux is donorcontrolled, with rate $\mathrm{d}_{\mathrm{p}}$. We did not distinguish the recycling of above- and belowground plant nutrients that we supposed to occur over the same spatial area, i.e. within the explored soil. Finally, mineralization describes the flux between the unavailable $\left(D_{E}, D_{U}\right)$ and the available nutrient pool $\left(\mathrm{N}_{\mathrm{E}}, \mathrm{N}_{\mathrm{U}}\right)$, within the explored (E) and unexplored (U) soil. We assumed that these fluxes were donor-controlled with the same rate $m_{D}$. For simplicity, we supposed that all nutrient cycling parameters that do not depend on the plant compartment $\left(i_{D}, i_{N}, m_{D}, l_{D}, l_{N}\right)$ were the same between the explored $(E)$ and unexplored $(U)$ zones. We developed two models, depending on whether the horizontal dynamics of the two zones are taken into account or not. 
Model without nutrient fluxes between the unexplored and explored soil

In the first model we assumed that individual plant always explore the same area of soil. We thus neglected all processes leading to an exchange of organic and mineral nutrients between the explored and unexplored areas of soil and therefore assumed that nutrient cycles within the two zones are independent. Given the different relations detailed above, the equations for this first model are:

$$
\begin{aligned}
& \frac{d P_{E}}{d t}=u_{N} N_{E} P_{E}-\left(d_{P}+I_{P}\right) P_{E} \\
& \frac{d D_{E}}{d t}=i_{D}+d_{P} P_{E}-\left(m_{D}+I_{D}\right) D_{E} \\
& \frac{d N_{E}}{d t}=i_{N}+m_{D} D_{E}-\left(u_{N} P_{E}+I_{N}\right) N_{E} \\
& \frac{d D_{U}}{d t}=i_{D}-\left(m_{D}+I_{D}\right) D_{U} \\
& \frac{d N_{U}}{d t}=i_{N}+m_{D} D_{U}-I_{N} N_{U}
\end{aligned}
$$

\section{Model with nutrient fluxes between the unexplored and explored soil}

In the second model we assumed that as individual plants die, the soil that they previously explored is converted to unexplored, and that at the same time unexplored patches can be colonized by new individuals, thus converting unexplored to explored soil. From the model perspective, these mechanisms are equivalent to fluxes of nutrients between the explored and unexplored zones, which we modelled by applying Levins' (1969) patch model to the first model (fluxes between the two zones are shown by dashed arrows on Figure 1). This new model has two more parameters, the plant turnover rate $\mu$ and the plant colonization rate $\mathrm{c}$ that determining the reduction and increase in plant exploration, respectively.

$$
\frac{d e}{d t}=c e(1-e)-\mu e
$$

Considering a dynamic equilibrium where the proportion of soil explored e remains constant, i.e. $\mathrm{de} / \mathrm{dt}=0$ leads to

$$
\mu=c(1-e)
$$

when $\mathrm{e} \neq 0$.

This last equation allows us to use the mortality rate $\mu$ as the only indicator of the intensity of fluxes between explored or unexplored soil.

There are four lateral fluxes from $P_{E}$ and $D_{E}$ to $D_{U}$, from $N_{E}$ to $N_{U}$, from $D_{U}$ to $D_{E}$ and from $\mathrm{N}_{U}$ to $\mathrm{N}_{\mathrm{E}}$ (Figure 1). For an easier comparison of the system properties for different values 
of $\mu$, we suppose that plant mortality $\left(d_{P}\right)$ is not affected by these dynamics: whatever the value of $\mu$, nutrient outflux from $P_{E}$ is $\left(d_{P}+l_{P}\right) P_{E}$. From the flux $d_{P} P_{E}, \mu$ e $P_{E}$ goes to $D_{U}$ and $\left(d_{P}-\mu e\right) P_{E}$ goes to $D_{E}$ (Figure 1). Biological relevance of the model implies that: $\mu \mathrm{e}<\mathrm{d}_{\mathrm{P}}$. The equations for this second model are:

$$
\begin{aligned}
& \frac{d P_{E}}{d t}=u_{N} N_{E} P_{E}-\left(d_{P}+I_{P}\right) P_{E} \\
& \frac{d D_{E}}{d t}=i_{D}+\left(d_{P}-\mu e\right) P_{E}+\mu e D_{U}-\left(m_{D}+I_{D}+\mu e\right) D_{E} \\
& \frac{d N_{E}}{d t}=i_{N}+m_{D} D_{E}+\mu e N_{U}-\left(u_{N} P_{E}+I_{N}+\mu e\right) N_{E} \\
& \frac{d D_{U}}{d t}=i_{D}+\mu e\left(P_{E}+D_{E}\right)-\left(m_{D}+I_{D}+\mu e\right) D_{U} \\
& \frac{d N_{U}}{d t}=i_{N}+m_{D} D_{U}+\mu e N_{E}-\left(I_{N}+\mu e\right) N_{U}
\end{aligned}
$$

Because this model was not analytically tractable, we studied its behaviour by running numerical simulations and numerical stability was ensured using the Routh-Hurwitz criterion.

\section{Relationships between space exploration and nutrient cycling parameters}

Our hypothesis of a trade-off between soil exploration and occupation (see Introduction) can be expressed by several ways depending on the process considered. In this study, we explored three mathematical trade-offs: a negative relationship between nutrient uptake $\left(\mathrm{u}_{\mathrm{N}}\right)$ or mineralization $\left(\mathrm{m}_{\mathrm{D}}\right)$ rates and soil exploration $(\mathrm{e})$, and a positive relationship between the loss of available nutrients $\left(l_{N}\right)$ and soil exploration (e). Thereafter, every parameter or variable that is function of soil exploration will be notified by adding "(e)" to its symbol.

In the main text, we focus on the case of a linear trade-off between the nutrient uptake rate and soil exploration:

$$
u_{N}(e)=u_{N}^{1}\left(1+\beta_{U N}(1-e)\right)
$$

where $u_{N}^{1}$ is the rate of nutrient uptake when all the soil is filled by the roots $(e=1)$, and $\beta_{U N}$ is the strength of the trade-off, i.e., the greater $\beta_{U N}$, the greater $u_{N}(e)$ when $e<1$. This 
relationship is supposed to be true above a threshold value $e_{\min }$ under which decreasing soil exploration decreases the uptake efficiency due to competition between roots. We explored other mathematical forms for this trade-off (Appendices $1 \& 2$ ). The cases of trade-offs between soil exploration e and available nutrient loss rate $1_{N}(e)$ or $m_{D}(e)$ are developed in Appendix 3.

\section{Parametrisation}

Our models can be applied to any single-nutrient limited system (e.g. N, P, K), under the hypothesis used in our modelling approach. To test quantitatively our model in two contrasted ecosystems, we focused on nitrogen cycling in: (1) Lamto, a tropical, humid African savanna in Côte d'Ivoire (Abbadie et al. 2006), and (2) a temperate upland pasture in United Kingdom (Batey 1982). Parameter values are given in Appendix 1. These two ecosystems are representative of many temperate and tropical grasslands and are characterized by contrasting horizontal root distributions. Long-lived tussock grasses are dominant in the savanna of Lamto and have a spatially concentrated root system leaving large parts of the soil unexplored (Abbadie et al. 2006). In temperate humid grasslands, grass cover is continuous and measurements of root absorption zones (Pecháčková et al. 2004) suggest that there is a strong overlap between the below-ground zones of influence of individuals, which backs the idea that all the available soil is explored in these systems.

\section{Partial recycling efficiencies and system closure}

We defined partial recycling efficiencies $\alpha_{P}, \alpha_{D}$, and $\alpha_{N}(e)$ that quantify the proportion of fluxes out of a compartment that reaches the next one for $P, D$ and $N$ compartments, respectively (Barot et al. 2007).

$$
\begin{aligned}
& \alpha_{P}=\frac{d_{P}}{d_{P}+I_{P}} \\
& \alpha_{D}=\frac{m_{D}}{m_{D}+I_{D}} \\
& \alpha_{N}(e)=\frac{u_{N}(e) P_{E}}{I_{N}+u_{N}(e) P_{E}}
\end{aligned}
$$

We defined the system closure $\Omega(\mathrm{e})$ as the product of all partial recycling efficiencies, which can be interpreted as the proportion of nutrients taken up by plants that come from the recycling of their own dead material:

$$
\Omega(e)=\alpha_{P} \alpha_{D} \alpha_{N}(e)
$$




\section{Results}

\section{Equilibrium and stability conditions of the first model}

The first model (Eq. 3) has only one non-trivial equilibrium:

$$
\begin{aligned}
& P_{E}^{*}=\frac{1}{d_{P}\left(1-\alpha_{P} \alpha_{D}\right)}\left(\alpha_{P}\left(i_{N}+\alpha_{D} i_{D}\right)-\frac{d_{P} l_{N}}{u_{N}(e)}\right) \\
& D_{E}^{*}=\frac{\alpha_{D}}{m_{D}\left(1-\alpha_{P} \alpha_{D}\right)}\left(\alpha_{P} i_{N}+i_{D}-\frac{d_{P} l_{N}}{u_{N}(e)}\right) \\
& N_{E}^{*}=\frac{d_{P}}{\alpha_{P} u_{N}(e)} \\
& D_{U}^{*}=\frac{\alpha_{D} i_{D}}{m_{D}} \\
& N_{U}^{*}=\frac{i_{N}+a_{D} i_{D}}{l_{N}}
\end{aligned}
$$

For equilibrium plant nutrient stock $\mathrm{P}_{\mathrm{E}}{ }^{*}$ and soil unavailable nutrients $\mathrm{D}_{\mathrm{E}}{ }^{*}$ to be defined, we must have $\alpha_{P} \alpha_{D}>1$, which translates into $1_{P}$ or $1_{D}>0$ (see eq. 8). To be biologically relevant, all nutrient stocks have to be positive. In the case of $\mathrm{P}_{\mathrm{E}}{ }^{*}$ and $\mathrm{D}_{\mathrm{E}}{ }^{*}$, this yields a single condition:

$$
R(e)=\frac{\alpha_{P} u_{N}(e)\left(i_{N}+\alpha_{D} i_{D}\right)}{d_{P} l_{N}}>1
$$

Under that condition, all positive equilibria are stable (Routh-Hurwitz criterion, Appendix 2).

As shown in Eq. 12 below, R(e) can be interpreted as the ratio between the inputs and outputs of nutrients if plants were growing in a formerly unexplored portion of soil at equilibrium. If $\mathrm{R}(\mathrm{e})>1$, the uptake of mineral nutrient is higher than losses from plant biomass so that plant growth is possible and

$$
R(e)=\frac{u_{N}(e) N_{U}^{*} P_{E}^{*}}{\left(d_{P}+I_{P}\right) P_{E}^{*}}
$$

\section{Conditions for which a reduced exploration maximizes plant nutrient stock}

Focusing on the size of the plant nutrient stock at equilibrium at the system scale $\mathrm{P}^{*}(\mathrm{e})$ and found values of soil exploration e which maximizes this variable. Using relations (7) to (10), a simple expression can be found for $\Omega(\mathrm{e})$ : 


$$
\Omega(e)=\alpha_{P} \alpha_{D} \frac{R(e)-1}{R(e)-\alpha_{p} \alpha_{D}}
$$

which leads to the following expression for plant nutrient stock:

$$
P^{*}(e)=\left[e\left(i_{N}+\alpha_{D} i_{D}\right)\right] \times\left[\frac{\Omega(e)}{1-\Omega(e)} \frac{1}{\alpha_{D} d_{P}}\right]
$$

The right-hand term of Eq. 14 can be described as a product between two functions of soil exploration. The first is a positive linear function of soil exploration e proportional to nutrient inputs in the mineral compartment of the soil. It expresses the increase in the size of the potentially available nutrient pool with increasing exploration. The second is an increasing function of system closure: the more efficient recycling in the overall system, the higher the plant nutrient stock. Figure 2 illustrates the resulting shape of plant nutrient stock as a function of soil exploration.

Without trade-off $\left(\mathrm{u}_{\mathrm{N}}(\mathrm{e})=\mathrm{u}_{\mathrm{N}}^{1}\right)$, the second term of the product is constant and $\mathrm{P}^{*}(\mathrm{e})$ is an increasing function of soil exploration. In this case, plant nutrient stock is always maximized when plants explore all the available soil $(e=1)$.

Whenever there is a trade-off between nutrient cycling efficiency $\left(\mathrm{u}_{\mathrm{N}}(\mathrm{e})\right)$ and soil exploration (e), plant nutrient stock at equilibrium $\mathrm{P}^{*}(\mathrm{e})$ becomes the product of increasing (nutrient inputs) and decreasing (nutrient cycling) functions of soil exploration e (Eq. 14). In that case, $\mathrm{P}^{*}(\mathrm{e})$ has a local maximum for a value of soil exploration noted $\mathrm{e}_{\mathrm{P} \text {. The }}$ exploration strategy that optimizes plant nutrient stock depends on the biological relevance of this value, which cannot exceed 1 (Fig. 2). If $e_{\mathrm{P}} \geq 1$ (case (a) on Fig. 2), plant biomass is maximized when the plant explores all the available space. If $e_{\mathrm{P}}<1$ (cases (b) and (c) on Fig.2), a restricted soil exploration can maximize plant nutrient stock. Note that in case (c), $\mathrm{P}^{*}$ becomes negative before $\mathrm{e}=1$, i.e. exploration above a given threshold $\mathrm{e}_{\mathrm{P}}<1$ yields a zero plant nutrient stock.

By the use of partial derivation, the analytical expression for optimum soil exploration $\mathrm{e}_{\mathrm{P}}$ can be calculated in the case of the linear trade-off:

$$
\mathrm{e}_{\mathrm{P}}=\frac{1}{\beta_{\mathrm{UN}}}\left(1+\beta_{\mathrm{UN}}-\sqrt{\frac{1+\beta_{\mathrm{UN}}}{\mathrm{R}(1)}}\right)
$$

In this case, $e_{\mathrm{P}}<1$ is equivalent to:

$$
R(1)<1+\beta_{U N}
$$

Low values of $e_{P}$ are thus favoured by low $R(1)$ ratio and high trade-off strength $\left(\beta_{U N}\right)$. According to the definition of $\mathrm{R}(\mathrm{e})$ (Eq. 11), $\mathrm{R}(1)$ decreases with the mineral nutrient content of the unexplored soil at equilibrium $\left(\mathrm{N}_{\mathrm{U}}{ }^{*}\right)$. This can be due to low inputs of nutrients to the system $\left(i_{D}\right.$ and $\left.i_{N}\right)$ and low recycling efficiencies $\alpha_{D}$ and $\alpha_{P}$, high mineral losses $1_{\mathrm{N}}$ or a high plant mortality $\mathrm{d}_{\mathrm{P}}+\mathrm{l}_{\mathrm{P}}$. 


\section{Generalisation to other trade-offs}

Although being qualitatively similar, other expressions for the trade-off between nutrient uptake rate $\mathrm{u}_{\mathrm{N}}(\mathrm{e})$ and soil exploration affect the mathematical expression of the value of soil exploration that maximises plant nutrient stock ( $\mathrm{e}_{\mathrm{P}}$; Appendix 2). With other trade-offs (negative relationship between soil exploration e and mineralisation rate $\mathrm{m}_{\mathrm{D}}(\mathrm{e})$ or positive relationship between e and the rate of available nutrient loss $\left.1_{\mathrm{N}}(\mathrm{e})\right)$. $\mathrm{P}^{*}(\mathrm{e})$ follows a similarly shaped curve with more complex analytical expressions (Appendix 3).

\section{Application to nitrogen cycling in two contrasting ecosystems}

For a given value of trade-off strength $\beta_{\mathrm{UN}}$, the model predicts a maximization of plant nutrient stock when soil is partly unexplored at Lamto, whereas in the British pasture plant nutrient stock is maximized when all the soil is explored (as expressed by $\mathrm{d}_{\mathrm{P}} \mathrm{P}^{*}(\mathrm{e})$ on Figures $3 a$ and $b$ ).

\section{Consequences of reduced soil exploration on soil nutrient stocks and losses}

By construction, any trade-off between soil exploration (e) and nutrient cycle parameters $\left(\mathrm{u}_{\mathrm{N}}, \mathrm{m}_{\mathrm{D}}\right.$ or $\mathrm{l}_{\mathrm{N}}$ ) leads to a positive relationship between e and the closure of the system $\Omega(\mathrm{e})$ (Eqs. 8 \& 9), as illustrated by Figure 3c,d in the case of nitrogen cycling in tropical savanna and temperate pastures. As we consider a flux between inputs and outputs of nutrients from our system, total nutrient losses do not vary with soil exploration. Still, any strategy that maximizes plant nutrient stock mechanically minimizes the nutrient losses from soil $\left(\mathrm{L}^{*}\right)$ as:

$$
L^{*}(e)=I_{D} D^{*}(e)+I_{N} N^{*}(e)=i_{D}+i_{N}-I_{P} P^{*}(e)
$$

Considering soil available $\left(\mathrm{N}^{*}\right)$ and unavailable $\left(\mathrm{D}^{*}\right)$ nutrient stocks at equilibrium, soil exploration value $\mathrm{e}_{\mathrm{P}}$ maximizes $\mathrm{D}^{*}$ with $\mathrm{P}^{*}$, and minimizes $\mathrm{N}^{*}$. Under specific conditions (Appendix 2), the total nutrient content of the system $\mathrm{T}^{*}$ is maximised at $\mathrm{e}_{\mathrm{p}}$. These results are illustrated in the case of the nitrogen cycle in Lamto savana and the British grassland in Figure 3a,b.

\section{Effects of the spatial dynamics of soil exploration}

Our second model was not analytically tractable and no simple general conditions arose for a positive and stable equilibrium. Figure 4 was obtained from numerical simulations with Lamto parameters. It shows the plant nutrient stock $\mathrm{P}^{*}$ as a function of soil exploration $\mathrm{e}$ and turnover rate $\mu$ (Appendix 4). In that case, the soil exploration value e e maximizing plant biomass increased with the mortality/colonisation ratio $\mu$ and decreased with the trade-off strength $\beta_{\mathrm{UN}}$ (Fig. 4). 


\section{Discussion}

\section{Conditions for the emergence of a strategy limiting horizontal exploration of soil}

The analysis of our two models leads to three necessary conditions for a restricted exploration to be beneficial for plants. First, there must be a trade-off between soil exploration and nutrient cycling processes such as nutrient uptake $\left(\mathrm{u}_{\mathrm{N}}\right)$, mineralization $\left(m_{D}\right)$ or the loss of soil available nutrients $\left(l_{N}\right)($ Eq. 7$)$. Second, soil ability to retain nutrients or external inputs of nutrients must be 'low' (Eq. 16). Third, the spatial dynamics between the unexplored and explored areas must be 'slow' (Fig. 4).

\section{Existence of occupation/exploration trade-offs}

A trade-off between soil exploration and nutrient cycling rates (such as nutrient uptake $\left(u_{N}\right)$, mineralization $\left(m_{D}\right)$ or the loss of soil available nutrients $\left.\left(1_{N}\right)\right)$ is necessary for a restricted exploration of the soil to be beneficial. Our in-depth analysis of nutrient uptake showed that the outcome of the model also depends on the strength and the shape of the trade-offs considered. The hypothesis of a trade-off between the size of the foraging area and its control is common in the context of plant competition (Aikio 2004). It applies, for example, to the guerilla vs. phalanx growth forms of clonal plants (Harper 1980). For equal plant biomasses, plants with a phalanx behaviour have a denser distribution of their ramets than guerilla plants (that spread over a large area) and are consequently more competitive but over a smaller area of soil. In this study, we enlarge the scope of this trade-off to plantsoil feedbacks affecting nutrient cycling. Several studies have documented various nutrient cycling processes, such as mineralization or nitrification, that are positively or negatively correlated to root density (Lata et al. 2000, Lambers et al. 2006, Shahzad et al. 2012). They support the intuitive idea that sparser root systems control nutrient cycling less efficiently than denser ones. Considering the vertical heterogeneities of roots, not studied here, may provide an additional argument to support the exploration/occupation trade-off hypothesis. Investing more into deep roots (at the expense of horizontal exploration) may provide a mean to minimize nutrient losses through leaching (Mareschal et al. 2013).

The existence of exploration/occupation trade-offs needs to be confirmed by further studies, and the precise shape of these trade-off should be documented. Empirical confirmation of these trade-offs can come from field studies that quantify root distribution at the whole plant scale and correlate it to nutrient fluxes (e.g. Lata et al. 2000). The application of indirect measurement of the zone of influence (Casper et al. 2003, Hartle et al. 2006) applied to both uptake and exudation processes may provide an alternative to the difficult excavation of whole root systems.

In complement, more mechanistic modelling approaches could also give a better insight into the functioning of plant-soil feedbacks at different scales like the rhizosphere (Hinsinger et al. 2009, 2011b) or the whole root system (Darrah et al. 2006, Pagès 2011). In particular, models inherited from the Barber-Cushman approach (e.g. Raynaud et al. 2008, Raynaud 2010), that simulate absorption and exudation around individual roots should help

\footnotetext{
'This article is protected by copyright. All rights reserved.'
} 
to identify which nutrients, and the conditions for which increased density would lead to better absorption efficiency and lower nutrient losses . Such models could also contribute to determine a more realistic shape for the trade-offs we have hypothesized.

\section{Nutrient cycling properties}

The second condition that has been identified for a beneficial restriction of soil exploration , i.e. a low mineral nutrient availability, is verified when (i) nutrient inputs in the soil are low and/or (ii) soil recycling efficiencies or soil nutrient availability are low, e.g. for high leaching rates. This condition is rather intuitive: if a soil is intrinsically nutrient rich, limiting soil exploration deprives plants of a larger quantity of mineral nutrients. This condition also suggests that the importance of the exploration/occupation trade-off will strongly depend on the relative abundances of limiting nutrients, their mobility within the soil solution, the respective root uptake capacities or nutrient affinity to soil substrates. At the moment, the $\mathrm{N}$ cycle is better documented than the $\mathrm{P}$ cycle and future studies may well document mechanisms that link root foraging strategies, root density and fluxes of phosphorus, leading to the kind of trade-offs hypothesized here (Hinsinger et al. 2011a). The same approach could also be applied to potassium that also appears to be an important limiting nutrient in many tropical systems (Manning 2010, Santiago et al. 2012). In general, condition (2) applies quite well to many wet tropical soils, that tend to have low organic matter content, low cation-exchange capacities and are subject to intense leaching (Sanchez and Logan 1992, Abbadie et al. 2006).

Slow spatial dynamics of plant-soil interactions

The benefit of a restricted exploration increases with the spatial stability of the area of soil explored. Intuitively, such a stability increases the benefits of controlling nutrient cycling because locally increasing resource availability is more beneficial if plants exploit these local resources more continuously in time. Spatial stability is a function of plant life history traits: perennial plants explore the same volume of soil for longer durations than annual plants, that are less susceptible to benefit from the recycling of their own dead roots. This is consistent with results pointing at the capacity of perennial tropical grasses, that are probably very long-lived (Abbadie et al. 2006), to control nutrient cycling (Abbadie et al. 1992, Yé et al. 2015). However, the spatial stability of soil exploration can also be enhanced over generations by other traits such as low dispersal or nursing effects that favour recruitment of seedlings near the parent plants (Pugnaire et al. 1996). Factors influencing plant or root mortality, such as fire regimes, herbivory, or the presence of pathogens (Hendriks et al. 2013) should also affect the spatial stability of soil exploration.

\section{Relevance of the exploration/occupation trade-off in the field}

We listed in the introduction some hypotheses proposed to explain the limitation of the horizontal extent of soil exploration: structural constraints (Lynch and Ho 2005), response

\footnotetext{
'This article is protected by copyright. All rights reserved.'
} 
to soil heterogeneities (Hodge 2004) or avoidance of competitors (Schenk et al. 1999). These hypotheses do not necessarily exclude each other and do not exclude our hypothesis that exploration limitation is the consequence of exploration/occupation trade-offs. However the explanatory power of each of these hypotheses to account for observed roots distributions needs to be discussed, by considering several of our simplifying assumptions.

\section{Soil exploration and its quantification}

Our parameter of soil exploration (e) quantifies soil exploration at the scale of a population, considered in a dynamic equilibrium. Moreover we hypothesized a clear-cut distinction between the soil explored and unexplored by plants. These assumptions result partly from the difficulty of building a simple model linking soil exploration and nutrient cycling. The most direct application of this framework to real plants is the case of perennial plants with a clonal reproduction, with ramets either spread over a large surface or concentrated in tufts (see the "Phalanx vs. Guerilla" metaphor; Lovett Doust 1981). In this case, there is a correspondence between the above- and below-ground biomass distribution (Abbadie et al. 2006) and soil exploration is a direct consequence of the organization of individual ramets (Harper 1980). However, applying this framework to other plants raises two important problems: (i) root distribution around individual plants is generally continuous (Casper et al. 2003) and obeys to architectural constraints (Lynch 1995) and (ii) root exploration at the scale of a population is a complex outcome of plant demography and individual development, including complex plant-soil interactions at both scales. To take these points into account, the efficiency of a restricted soil exploration should be tested within a spatially explicit, individual-based approach, parametrized by the shapes of zones of influence measured in the field (Pecháčková et al. 2004, Hartle et al. 2006).

The vast majority of vascular plants develop mycorrhizal association with soil fungi that provide them an important share of nutrients such as nitrogen or phosphorus (Heijden et al. 2015). This point was not taken into account explicitly by our model, but our hypothesis of a trade-off between exploration and occupation could be generalized to that case. For example, mycorrhizal associations can enhance the efficiency of nutrient cycling by minimizing nutrient losses (Heijden et al. 2015), but its high carbon cost may prevent plants from growing new roots.

\section{Resource heterogeneities and inter-plant competition}

A wide range of studies have shown how root distributions adapt to the heterogeneities of soil nutrients and the presence of competitors (Schenk et al. 1999, Hodge 2004).

Competition between plant individuals has indeed been predicted to influence the level of soil exploration plants should have evolved (O'Brien et al. 2007): in some cases an extensive soil exploration can be selected, which should lead to the overlap of individual root systems and to continuous distributions of root densities. These mechanisms are not taken into account in our framework but are very influential for root foraging strategies in

\footnotetext{
'This article is protected by copyright. All rights reserved.'
} 
the field. Plant territoriality (Schenk et al. 1999) and preferential root proliferation within nutrient-rich patches (Hodge 2004) are both plausible and complementary explanations for a restricted exploration of the soil. The deposition of aboveground litter (Xu et al. 2013) and the interception of litter and rainfall (Wezel et al. 2000) may also contribute to the formation of below-ground heterogeneities.

Taken together, our model suggests that the limitation of soil exploration can be beneficial when it allows to better control nutrient cycling, but several other mechanisms are already known to influence root distribution and soil exploration. All the involved mechanisms are complementary and it may be difficult to disentangle the influence of each mechanism in real cases. This may be overcome through an experimental approach, where nutrient supply heterogeneity and the presence of competitors can be controlled (Mommer et al. 2011). With such an approach, plant ability to control nutrient cycling may be assessed by providing nutrients in a more or less available form. Plant investment in exploration $v s$. occupation could be measured more accurately by measuring precise root traits such as root length density distribution or the investment in exudates production (Hodge et al. 1996).

\section{Next steps forward}

To test thoroughly our model with experiments and data several steps are required: (1) Test the hypotheses of our model, mainly to better document the general trade-off we hypothesise between soil exploration and soil occupation, i.e. the control on nutrient cycling as a function of root density. This could be achieved by documenting at the same time, root horizontal distribution, and links between root density and nutrient cycling processes (e.g. mineralization, nitrification, leaching) for several plant species or different genotypes of the same species that have different horizontal root architectures. (2) Test experimentally how a restricted soil exploration for a given species is affected by the overall nutrient availability, the intensity of competition, and heterogeneity in nutrient availability. (3) Test the model predictions for the conditions leading to a beneficial restriction of soil exploration by comparing in many different ecosystems from different climate zones, overall nutrient availability, as well as the horizontal root distribution of plants and the extension of individual root systems.

\section{Consequences of root exploration limitation strategies on ecosystems functioning and potential applications}

In our model, restricted soil exploration not only enhances plant nutrient stock, but also improves nutrient cycling at the whole system scale (nutrient cycle closure $\Omega(\mathrm{e})$ ). The rate of nutrient loss from soil compartments $\left(\mathrm{L}^{*}\right)$ is lowered while soil unavailable nutrient stock $\left(D^{*}\right)$ is maximized. This is consistent with the common observation of organic matter accumulation under tussock grasses (Derner and Briske 2001), which are used to increase fertility during fallows (Somé et al. 2006).

Another, more direct, consequence of soil exploration limitation is the creation of spatial heterogeneity, with patches of soil densely explored by roots and others left unexplored. A

\footnotetext{
'This article is protected by copyright. All rights reserved.'
} 
point that should be analysed in further studies is the contribution of this limitation of soil exploration to the creation of islands of fertility, as often observed under perennial plants and tussock grasses (Wezel et al. 2000, Derner and Briske 2001).

The conditions discussed above as well as our numerical applications suggest that the strategy of limited exploration applies quite well to perennial tussock grasses growing within wet tropical or semi-arid desert soils, or more generally within ecosystems where balanced foraging strategies for water and nutrients are more focused on nutrients. Compared to shrubs and trees, grasses are generally less able to grow roots at long distance (Schenk and Jackson 2002) and are thus less likely to benefit from large-scale heterogeneities of soil resources. However, they have a high plasticity in root proliferation. For example, Schwinning and Ehleringer (2001) showed that grasses in arid ecosystems can adapt to the type of water resource (pulse vs. deeper soil water) by switching from shallow to deep root systems. Reduced soil exploration could also enhance, amongst others, plant ability to control microbial processes such as nitrification (e.g., Biological Nitrification Inhibition, Subbarao et al. 2006) and contribute to a more conservative nitrogen cycling (Abbadie et al. 1992, Yé et al. 2015).

Finally, reduced soil exploration could be an interesting trait for producing more nutrient-efficient crops, that are needed to develop more sustainable agricultural systems (Weiner et al. 2010, Malézieux 2011, Subbarao et al. 2013). Although the measurement of below-ground traits is more difficult than the measurement of above-ground traits (Roumet et al. 2006), such traits could play an important role in future selection of new varieties (White et al. 2013). Our study suggests in particular that a balance will have to be found between traits involved in soil exploration (e.g. specific root length) and the control of nutrient cycling (e.g. BNI systems leading to low-nitrifying rates - Subbarao et al. 2013). We hypothesize that modern intensive agriculture has so far more relied on the selection of crop varieties that are efficient at soil exploration, i.e. uptake of mineral fertilizers, and not on nutrient conservation. Our model gives more arguments for the development of perennial cereals (Cox et al. 2006) that would restrict soil exploration but increase their control on nutrient availability because of their permanent dense root systems.

\section{Acknowledgements}

We thank Simon Boudsocq, Sébastien Fontaine and Emma Rochelle-Newall for their useful advices and comments on a previous version of this manuscript. This work was funded by the ANR SAVARID of the French National Research funding Agency (ANR) under the reference SAVARID (ANR-11-CEPL-0003). 
Abbadie, L. et al. 1992. Independance of savanna grasses from soil organic matter for their nitrogen supply. - Ecology 73:608-613.

Abbadie, L. et al. 2006. Lamto : Structure, Functioning and Dynamics of a Savanna Ecosystem. - Springer.

Aikio, S. 2004. Competitive asymmetry, foraging area size and coexistence of annuals. Oikos 104:51-58.

Barot, S. et al. 2007. Nutrient cycling efficiency explains the long-term effect of ecosystem engineers on primary production. - Funct. Ecol. 21:1-10.

Batey, T. 1982. Nitrogen cycling in upland pastures of the UK. - Philos. Trans. R. Soc. Lond. B. Biol. Sci. 296:551-556.

Boudsocq, S. et al. 2009. Modelling approach to analyse the effects of nitrification inhibition on primary production. - Funct. Ecol. 23:220-230.

Casper, B. B. and Jackson, R. B. 1997. Plant competition underground. - Annu. Rev. Ecol. Syst. 28:545-570.

Casper, B. B. et al. 2003. Defining a plant's belowground zone of influence. - Ecology 84:2313-2321.

Cox, T. S. et al. 2006. Prospects for developing perennial grain crops. - Bioscience 56:649.

Darrah, P. R. et al. 2006. Modelling the rhizosphere: a review of methods for "upscaling" to the whole-plant scale. - Eur. J. Soil Sci. 57:13-25.

Derner, J. D. and Briske, D. D. 2001. Below-ground carbon and nitrogen accumulation in perennial grasses: A comparison of caespitose and rhizomatous growth forms. - Plant Soil 237:117-127.

Frank, D. D. A. et al. 2010. Grassland root communities: species distributions and how they are linked to aboveground abundance. - Ecology 91:3201-3209.

Frank, D. A. et al. 2015. Fine-scale belowground species associations in temperate grassland. - Mol. Ecol. 24:3206-3216.

Ge, Z. et al. 2000. The importance of root gravitropism for inter-root competition and phosphorus acquisition efficiency: results from a geometric simulation model. - Plant Soil 218:159-171. 
Gersani, M. et al. 1998. Density-dependent habitat selection in plants. - Evol. Ecol. $12: 223-234$.

Groot, J. J. R. et al. 1998. Description du système racinaire de trois espèces fourragères en zone soudano-sahélienne : Andropogon gayanus, Vigna unguiculata et Stylosanthes hamata. - Biotechnol. Agron. Soc. Environ. 2:106-119.

Guevara, A. et al. 2009. Phenotypic plasticity of the coarse root system of Prosopis flexuosa, a phreatophyte tree, in the Monte Desert (Argentina). - Plant Soil 330:447464.

Harper, J. L. 1980. Plant demography and ecological theory. - Oikos 35:244-253.

Hartle, R. T. et al. 2006. Horizontal and vertical zones of influence for root systems of four Mojave Desert shrubs. - J. Arid Environ. 64:586-603.

van der Heijden, M. G. A. et al. 2015. Mycorrhizal ecology and evolution: the past, the present, and the future. - New Phytol. 205:1406-1423.

Hendriks, M. et al. 2013. Independent variations of plant and soil mixtures reveal soil feedback effects on plant community overyielding. - J. Ecol. 101:287-297.

Hinsinger, P. et al. 2009. Rhizosphere: biophysics, biogeochemistry and ecological relevance. - Plant Soil 321:117-152.

Hinsinger, P. et al. 2011a. P for two, sharing a scarce resource: soil phosphorus acquisition in the rhizosphere of intercropped species. - Plant Physiol. 156:1078-86.

Hinsinger, P. et al. 2011b. Acquisition of phosphorus and other poorly mobile nutrients by roots. Where do plant nutrition models fail? - Plant Soil. 348:29 - 61.

Hodge, A. 2004. The plastic plant: root responses to heterogeneous supplies of nutrients. New Phytol 162:9 - 24.

Hodge, A. et al. 1996. A novel method for characterisation and quantification of plant root exudates. - Plant Soil 184:97-104.

Lambers, H. et al. 2006. Root structure and functioning for efficient acquisition of phosphorus: Matching morphological and physiological traits. - Ann. Bot. 98:693713. 
Lata, J.-C. et al. 2000. Relationships between root density of the African grass Hyparrhenia diplandra and nitrification at the decimetric scale: an inhibition-stimulation balance hypothesis. - Proc. R. Soc. B Biol. Sci. 267:595-600.

Levins, R. 1969. Some demographic and genetic consequences of environmental heterogeneity for biological control. - Bull. Entomol. Soc. Am. 15:237-240.

Lovett Doust, L. 1981. Population dynamics and local specialization in a clonal perenial (Ranunculus repens). - J. Ecol. 69:743-755.

Lynch, J. P. 1995. Root architecture and plant productivity. - Plant Physiol. 109:7-13.

Lynch, J. P. 2013. Steep, cheap and deep: An ideotype to optimize water and N acquisition by maize root systems. - Ann. Bot. 112:347-357.

Lynch, J. P. and Ho, M. D. 2005. Rhizoeconomics : Carbon costs of phosphorus acquisition. - Plant Soil:45-56.

Malézieux, E. 2011. Designing cropping systems from nature. - Agron. Sustain. Dev. $32: 15-29$.

Manning, D. A. C. 2010. Mineral sources of potassium for plant nutrition. A review. Agron. Sustain. Dev. 30:281-294.

Mareschal, L. et al. 2013. Nutrient leaching and deep drainage under Eucalyptus plantations managed in short rotations after afforestation of an African savanna: Two 7-year time series. - For. Ecol. Manage. 307:242-254.

Mommer, L. et al. 2011. Interactive effects of nutrient heterogeneity and competition: implications for root foraging theory? - Funct. Ecol. 26:66-73.

O’Brien, E. E. and Brown, J. S. 2008. Games roots play: effects of soil volume and nutrients. - J. Ecol. 96:438-446.

O’Brien, E. E. et al. 2007. Roots in space: a spatially explicit model for below-ground competition in plants. - Proc. R. Soc. B Biol. Sci. 274:929-935.

Pagès, L. 2011. Links between root developmental traits and foraging performance. - Plant. Cell Environ. 34:1749-60.

Pecháčková, S. et al. 2004. Horizontal and vertical distribution of root absorption zones of four common grass species in a mountain grassland. - New Phytol. 161:303-312. 
Pugnaire, F. I. et al. 1996. Facilitation between higher plant species in a semiarid environment. - Ecology 77:1420-1426.

Raynaud, X. 2010. Soil properties are key determinants for the development of exudate gradients in a rhizosphere simulation model. - Soil Biol. Biochem. 42:210-219.

Raynaud, X. et al. 2008. Plants may alter competition by modifying nutrient bioavailability in rhizosphere: a modeling approach. - Am. Nat. 171:44-58.

Roumet, C. et al. 2006. Suites of root traits differ between annual and perennial species growing in the field. - New Phytol. 170:357-68.

Sanchez, P. A. and Logan, T. J. 1992. Myths and science about the Chemistry and Fertility of Soils in the Tropics. - In: Myths and science of soils of the tropics Proceedings of an international symposium Las Vegas October 1989. pp. 35-46.

Santiago, L. S. et al. 2012. Tropical tree seedling growth responses to nitrogen, phosphorus and potassium addition. - J. Ecol. 100:309-316.

Schenk, H. J. and Jackson, R. B. 2002. Rooting depths, lateral root spreads and

below-ground/above-ground allometries of plants in water-limited ecosystems. - J.

Ecol. 90:480-494.

Schenk, H. J. et al. 1999. Spatial root segregation: are plants territorial? - Adv. Ecol. Res. 28:145-180.

Schwinning, S. and Ehleringer, J. R. 2001. Water use trade-offs and optimal adaptations to pulse-driven arid ecosystems. - J. Ecol. 89:464-480.

Shahzad, T. et al. 2012. Plant clipping decelerates the mineralization of recalcitrant soil organic matter under multiple grassland species. - Soil Biol. Biochem. 51:73-80.

Somé, N. A. et al. 2006. Amélioration du statut organique d'un sol ferrugineux tropical lessivé sous jachère artificielle à Andropogon spp. au Burkina Faso: effet des traitements sur la chimie. - Tropicultura 24:200-207.

Subbarao, G. V et al. 2006. Biological nitrification inhibition (BNI) - is it a widespread phenomenon? - Plant Soil 294:5-18. 
Subbarao, G. V et al. 2013. A paradigm shift towards low-nitrifying production systems: the role of biological nitrification inhibition (BNI). - Ann. Bot. 112:297-316.

Weiner, J. et al. 2010. Evolutionary Agroecology: the potential for cooperative, high density, weed-suppressing cereals. - Evol. Appl. 3:473-479.

Wezel, A. et al. 2000. Influence of shrubs on soil characteristics and their function in Sahelian agro-ecosystems in semi-arid Niger. - J. Arid Environ. 44:383-398.

White, P. J. et al. 2013. Root traits for infertile soils. - Front. Plant Sci. 4:193.

Xu, S. et al. 2013. Variability of above-ground litter inputs alters soil physicochemical and biological processes: A meta-analysis of litterfall-manipulation experiments. Biogeosciences 10:7423-7433.

Yé, L. et al. 2015. Contrasting impacts of grass species on nitrogen cycling in a grazed Sudanian savanna. - Acta Oecologica 63:8-15. 
Table Legend

Table 1: Meaning and units of variables and parameters for the two models.

Unit

$\begin{array}{lllll}\text { Variables } & \mathrm{P}_{\mathrm{E}} & \text { Plant } & \text { In the area explored by plants } \quad \mathrm{kg} \text { [nutrient].ha }{ }^{-1}\end{array}$

$\mathrm{D}_{\mathrm{E}} \quad$ Soil unavailable

nutrient

$\mathrm{N}_{\mathrm{E}} \quad$ Soil available

nutrients

$\mathrm{D}_{\mathrm{U}} \quad$ Soil unavailable

nutrient

In the unexplored area of soil

$\mathrm{N}_{\mathrm{U}} \quad$ Soil available

nutrients

P Plant Whole system scale

D Soil unavailable

nutrient

N Soil available nutrient

$\mathrm{T} \quad$ Ecosystem total stock

of nutrient

L Soil total nutrient $\quad \mathrm{kg}\left[\right.$ nutrient] $\mathrm{ha}^{-1} \cdot \mathrm{yr}^{-1}$

losses

Parameters

Percent of soil surface explored by plants

none

$\mathrm{i}_{\mathrm{D}} \quad$ Total input to D compartments

$\mathrm{kg}[$ nutrient $] \cdot \mathrm{ha}^{-1} \cdot \mathrm{yr}^{-1}$

$\mathrm{i}_{\mathrm{N}} \quad$ Total input to $\mathrm{N}$ compartments

$\mathrm{kg}\left[\right.$ nutrient].ha ${ }^{-1} \cdot \mathrm{yr}^{-1}$

$1_{\mathrm{P}}, 1_{\mathrm{D}}, 1_{\mathrm{N}} \quad$ Loss rates

$\mathrm{yr}^{-1}$

$\mathrm{u}_{\mathrm{N}}$

Nutrient uptake efficiency

ha.kg $[\text { nutrient }]^{-1} \cdot \mathrm{yr}^{-1}$

$\beta_{\mathrm{UN}}$

Strength of the trade-offs between soil exploration and

none

nutrient uptake efficiency

'This article is protected by copyright. All rights reserved.' 


$\begin{array}{llc}\mathrm{d}_{\mathrm{P}} & \text { Rate of litter deposition } & \mathrm{yr}^{-1} \\ \mathrm{~m}_{\mathrm{D}} & \text { Mineralization rate } & \mathrm{yr}^{-1} \\ \alpha_{\mathrm{D}}, \alpha_{\mathrm{P}} & \text { Recycling coefficients } & \mathrm{none} \\ \mathrm{c} & \text { Colonization rate (model 2) } & \mathrm{yr}^{-1} \\ \mu & \text { Turnover rate (model 2) } & \mathrm{yr}^{-1}\end{array}$

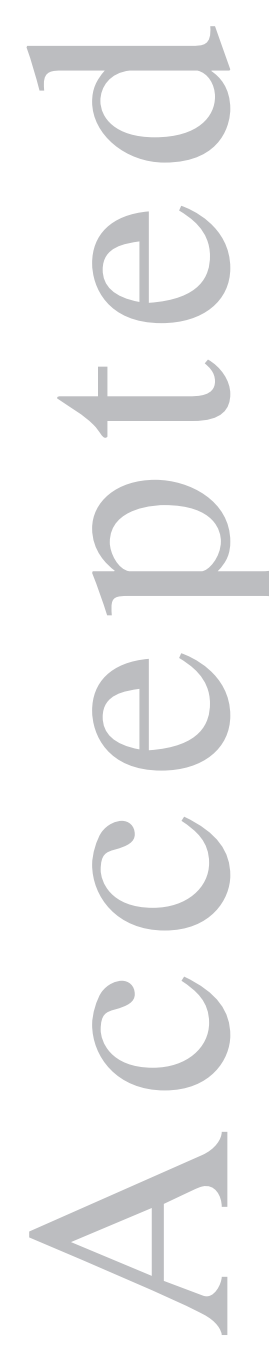

'This article is protected by copyright. All rights reserved.' 
Figure Legends

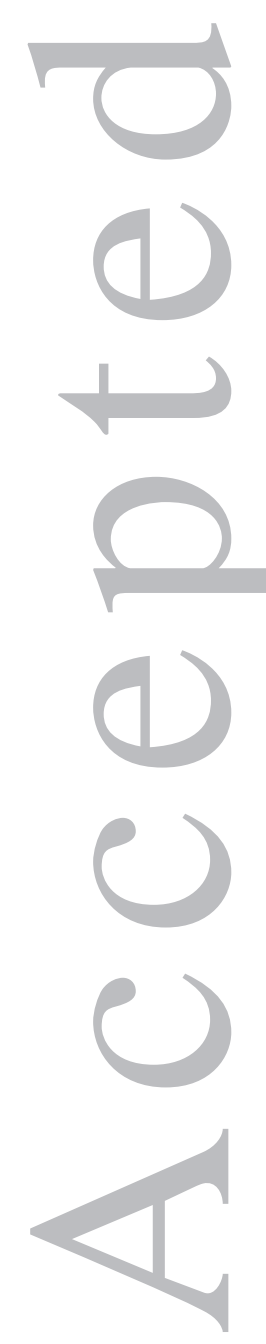

'This article is protected by copyright. All rights reserved.' 
Figure 1: Diagram of the models. We consider separately nutrient cycling within the soil explored by plants (within the grey dashed rectangle, subscript E) and nutrient-cycling in bare, unexplored soil (subscript $\mathrm{U}$ ). The proportion of soil explored is quantified by e (Figure 1). Nutrient cycles between five compartments: plants $\left(\mathrm{P}_{\mathrm{E}}\right)$, soil unavailable nutrients $\left(D_{E}\right.$ and $\left.D_{U}\right)$ and available nutrients $\left(\mathrm{N}_{\mathrm{E}}\right.$ and $\left.\mathrm{N}_{\mathrm{U}}\right)$. Arrows represent fluxes between nutrient pools within each zone of soil, with their mathematical expression. Plain arrows correspond to fluxes of model 1, while grey, dashed arrows are fluxes added to model 1 to form model 2.

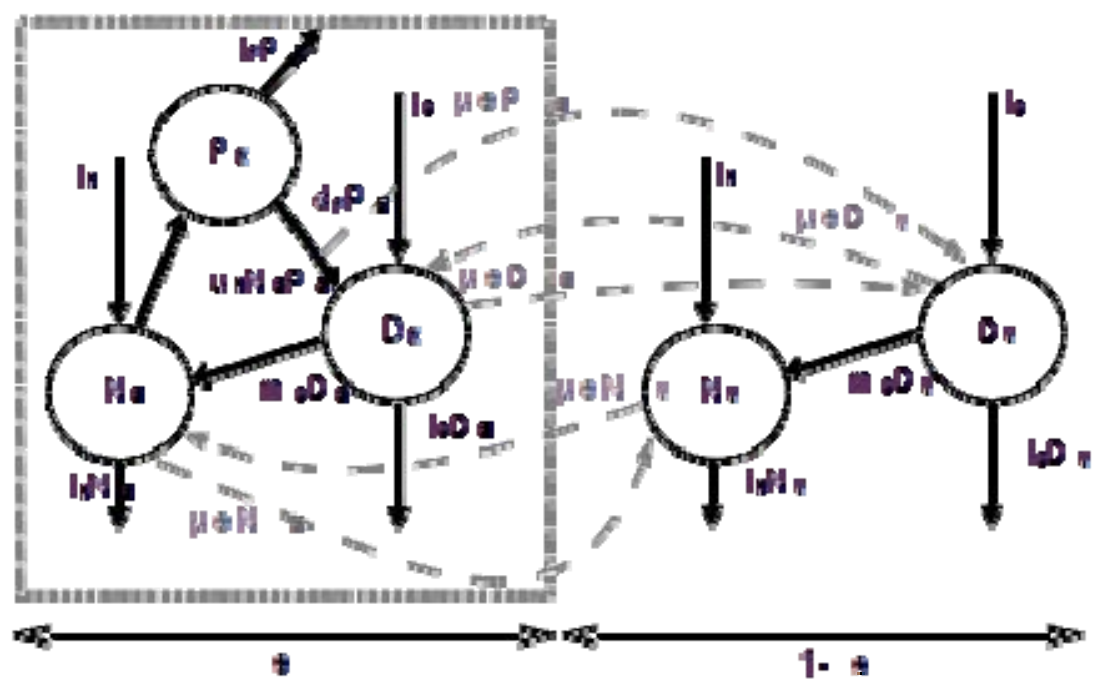

'This article is protected by copyright. All rights reserved.' 
Figure 2: Variation of plant nutrient stock at equilibrium $\mathrm{P}^{*}(\mathrm{e})$ with soil exploration (e) for a linear trade-off. Three different cases are possible analytically, depending on the relationships between local maximum and limit values for biological relevance. $\mathrm{e}_{\min }$ is a minimum for soil exploration that cannot be null while 1 is its maximum value, by definition. In case (a), the maximum of the curve is reached for $e_{\mathrm{P}}>1$. In that case, plant nutrient content is maximized when all the soil is explored. In (b), the maximum is reached for $\mathrm{e}_{\mathrm{P}}<1$, and plant nutrient content is always positive. In that case, the plant can explore all the space available, but maximizes its mineral nutrition when reducing lateral spread. In (c), as in (b), plant nutrient content is maximized for $\mathrm{e}_{\mathrm{P}}<1$ but reaches 0 for $\mathrm{e}_{0}<1$. In that case, the plant cannot spread over the entire surface available.

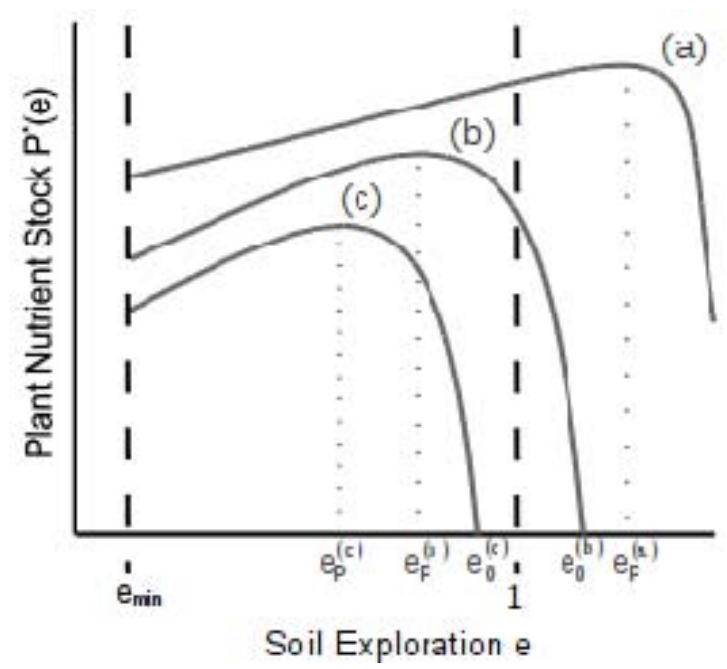

'This article is protected by copyright. All rights reserved.' 
Figure 3: General system properties estimated in the case of Lamto savanna ecosystem (left), and a British temperate grassland (right) with the linear trade-off and $\beta_{\mathrm{UN}}=1.4$. Panels (a) and (b) show different fluxes as functions of root lateral spread: plant mortality $\left(\mathrm{d}_{\mathrm{P}}\right.$ $\left.\mathrm{P}^{*}(\mathrm{e})\right)$ and soil organic $\left(\mathrm{l}_{\mathrm{D}} \mathrm{D}^{*}(\mathrm{e})\right)$, mineral $\left(\mathrm{l}_{\mathrm{N}} \mathrm{N}^{*}(\mathrm{e})\right)$ and total $\mathrm{N}$ losses $\left(\mathrm{L}^{*}(\mathrm{e})\right)$. Plant mortalities show that Lamto savanna and the British grassland correspond respectively in Figure 2 to the cases (b) and (a). Panels (c) and (d) show the relationship between the system closure $\Omega$ at equilibrium (equation 14 for definition) and soil exploration e.

(a)

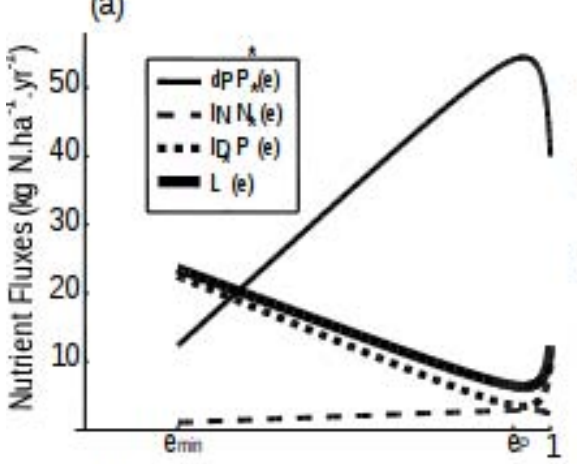

(c)

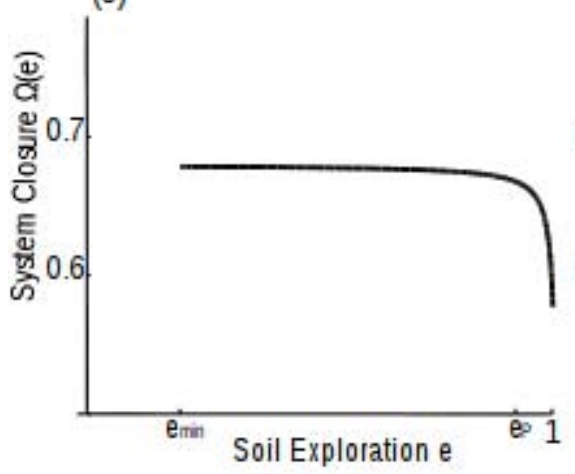

(b)

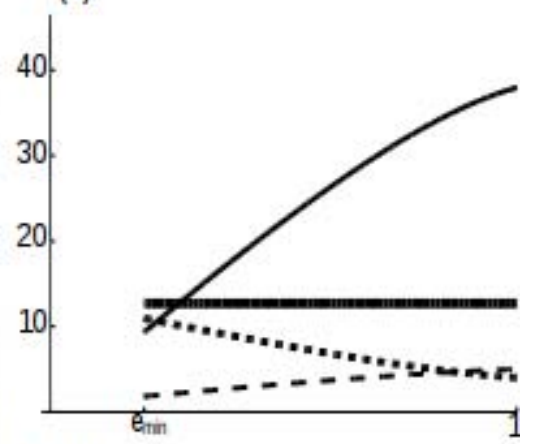

(d)

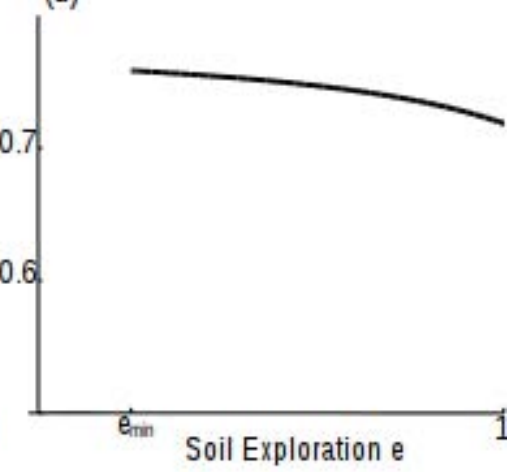

'This article is protected by copyright. All rights reserved.' 
Figure 4: The lateral spread maximizing biomass, $e_{\mathrm{P}}$ as a function of lateral fluxes intensity $\mu$ and trade-off strength $\beta_{\mathrm{UN}}$. Lamto parameter set was used for this figure. Low values of $e_{P}$ are obtained for low values of $\mu$ and high values of $\beta_{U N}$.

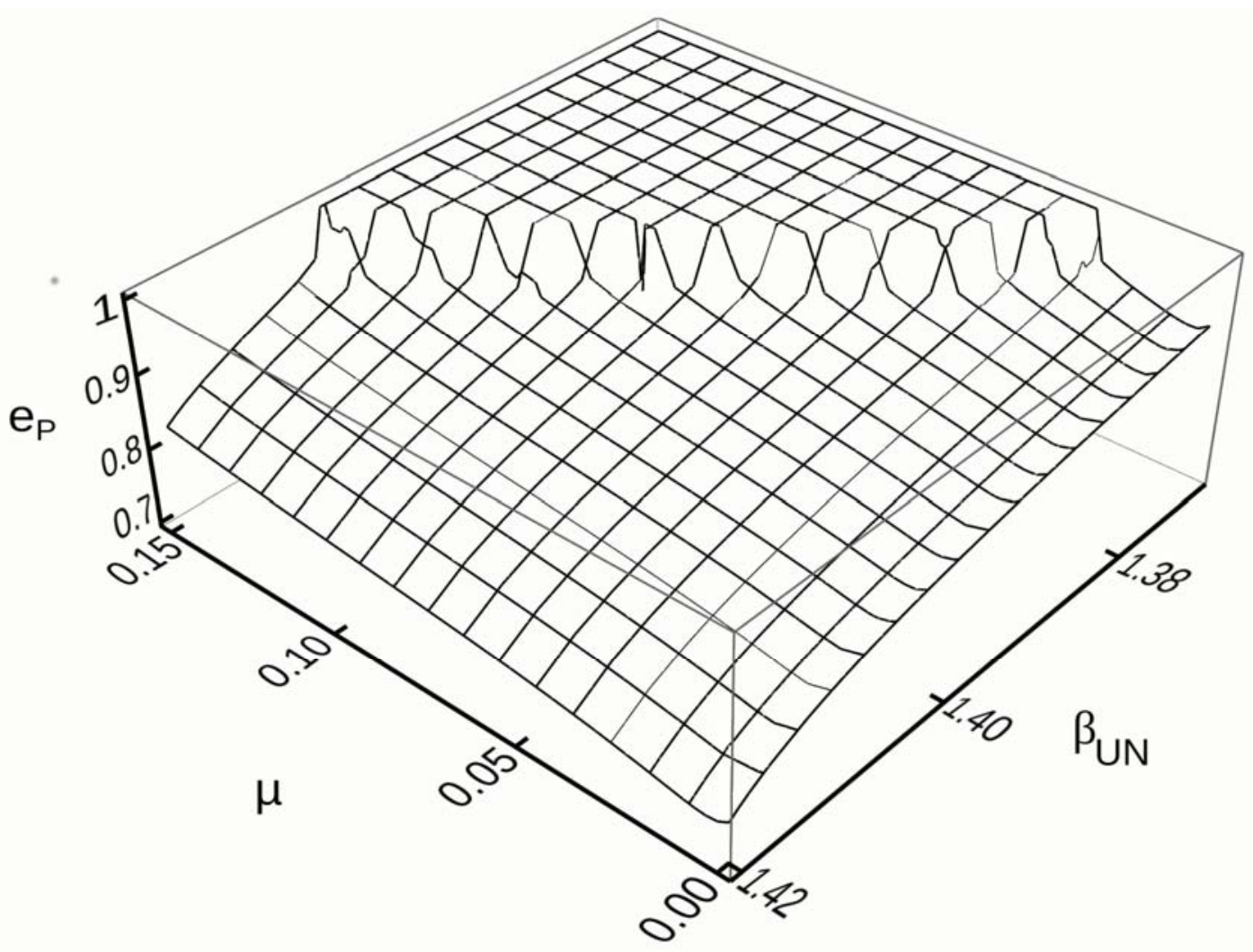

'This article is protected by copyright. All rights reserved.' 